\title{
Conserving biodiversity in New Zealand's lowland landscapes: does forest cover or pest control have a greater effect on native birds?
}

\author{
Jay Ruffell ${ }^{1 *}$ and Raphael K. Didham ${ }^{1,2}$ \\ ${ }^{1}$ School of Animal Biology, The University of Western Australia, 35 Stirling Highway, Crawley WA 6009, Australia \\ ${ }^{2}$ CSIRO Land and Water, Centre for Environment and Life Sciences, Underwood Ave, Floreat WA 6014, Australia \\ *Author for correspondence (Email: ruffell.jay@gmail.com)
}

Published online: 18 October 2016

\begin{abstract}
Effective biodiversity conservation in lowland New Zealand requires an understanding of the relative benefits of managing impacts of native forest loss versus controlling invasive species. We used bird count data from 195 locations across mainland northern New Zealand to examine how the abundance and richness of native forest birds varied across wide gradients of native forest cover (c. 0-100\%) and intensity of invasivespecies control ('eradication', 'high-intensity rat and possum', 'low-intensity rat and possum', 'periodic possum' and 'none'). Most response variables were significantly affected by forest cover, and this effect was typically non-linear: response variables declined rapidly below c. 5-10\% forest cover, but were relatively invariant to forest cover above this point. Pest control was found to affect surprisingly few species, with only kereru (Hemiphaga novaeseelandiae) and tui (Prosthemadera novaeseelandiae) being more abundant at pest controlled than uncontrolled sites for any pest control category. Species richness and 'total abundance' (abundance of all species combined) also increased at pest controlled sites, but effects were largely driven by responses of tui and kereru. Effects of eradication were far larger than effects of other pest control categories, while it was unclear whether 'low-intensity rat and possum' or 'periodic possum' control had any effects at all. Our results suggest that both managing levels of forest cover and controlling invasive mammals can benefit native forest birds, but the occurrence and magnitude of these benefits will be context-dependent. Managing forest cover may be relatively unimportant in landscapes with $>5-10 \%$ forest cover, while benefits of pest control may be limited unless intensive methods are used. Moreover, even intensive pest control may only benefit a small subset of species unless coupled with reintroduction of locally-extinct species. Combining these results with knowledge of the financial, ethical, and social constraints of different management options should provide a solid foundation for effective conservation decision-making in lowland environments.
\end{abstract}

Keywords: brushtail possum; forest loss; fragmentation; habitat loss; invasive species; land use change; ship rat

\section{Introduction}

Lowland ecosystems throughout the world are impacted by multiple co-occurring threats (Sala et al. 2000; Munns 2006; Wilson et al. 2007). These systems have typically experienced dramatic reductions in native vegetation cover to make way for production land uses, so habitat loss is usually seen as a major threat (Sala et al. 2000; Foley et al. 2011). However, native species in lowland ecosystems are frequently exposed to additional threats, such as invasive species, pollution, overharvesting, and climate change (Sala et al. 2000; Novacek \& Cleland 2001; Riley 2002; Wilson et al. 2007). These additional threats may impact biodiversity independently of habitat loss, or they may interact with it, resulting in combined effects that are larger or smaller than would be expected from the effects of either threat acting in isolation (Sala et al. 2000; Laurance \& Cochrane 2001; Didham et al. 2007). The challenge for conservation managers is to understand the relative benefits of managing the different threats within their management region, so that they can allocate their limited resources to the management actions that best achieve conservation goals.

In New Zealand, protecting biodiversity in lowland environments will be one of the biggest conservation challenges for the coming decades (Kelly \& Sullivan 2010). These environments make up around half of the total land area, so protecting the native species that occur within them will be a fundamental part of meeting the New Zealand
Biodiversity Strategy's goal of halting biodiversity declines across the full range of natural ecosystems (Craig et al. 2000; DOC \& MfE 2000). However, native forest cover has been drastically reduced in most lowland landscapes, pressure for further reduction is likely to increase as the human population grows, and these landscapes remain heavily underrepresented in protected area networks (Craig et al. 2000; Ewers et al. 2006; Kelly \& Sullivan 2010). Our ability to conserve native biodiversity in lowland environments is likely therefore to depend strongly on our understanding of the impacts of forest clearance, and the management strategies that can avoid or reduce these impacts.

For managers aiming to conserve native birds in New Zealand's lowland ecosystems, the key challenge will be to determine when resources should be spent managing the impacts of native forest loss (for example, by protecting against future forest clearance, replanting native trees, protecting seral vegetation to allow passive regeneration, or using exotic plantations to provide substitute habitat; Norton \& Miller 2000; Ewers et al. 2006; Ruffell et al. 2016), and when they should be spent managing the impacts of invasive mammals. Invasive mammalian predators (primarily rats Rattus rattus and $R$. norvegicus, brushtail possums Trichosurus vulpecula, and stoats Mustela erminea) are widely believed to be the primary threat, and many studies have demonstrated strong population-level impacts on a range of threatened species (reviewed in Innes et al. 2010). Invasive mammals are also 
known to eat the eggs, nestlings, and adults of non-threatened birds, and there is evidence that this individual-level predation can cause population-level impacts for at least some species (i.e. reduced adult abundance or reduced population viability; Armstrong et al. 2006; Innes et al. 2010; O’Donnell \& Hoare 2012). By contrast, research on the effects of native forest loss is limited. A handful of studies have demonstrated that forest loss has impacted native bird communities (Diamond 1984; Stevens 2006; Deconchat et al. 2009; Barnagaud et al. 2014), while several other studies have indicated that forest loss may even have greater impact than invasive mammals in some circumstances. Innes et al. (2010) suggested that forest loss may be the primary limiting factor for forest birds in New Zealand's more deforested regions. Similarly, Ruffell (2015) found that biodiversity offsetting programmes that used pest control to offset impacts of forest clearance on native birds were unlikely to be successful if forest cover was low to begin with, suggesting that forest loss may have larger effects than invasive mammals in low-cover landscapes. Nonetheless, our understanding of the relative impacts of forest loss versus invasive mammals in lowland landscapes is currently insufficient to make robust decisions about how limited conservation resources can be spent most effectively.

Where invasive mammals are deemed the primary threat, conservation managers typically undertake invasive-mammal control ('pest control'). However, methods of pest control are highly variable, differing in terms of devices used (e.g. poisons versus traps versus shooting), application method (aerial versus ground-based delivery of poisons), control intensity (density of traps and poisons, frequency of control), and species targeted, among other factors (Gillies 2002; Parkes \& Murphy 2003; Beausoleil et al. 2010). Different methods vary widely in their efficacy, cost, and humaneness (Warburton \& Norton 2009; Beausoleil et al. 2010; Scofield et al. 2011), yet our knowledge of which pest control regimes can achieve particular conservation goals remains poor (Ruffell et al. 2015). Understanding when limited resources can defensibly be spent on pest control (i.e. where control achieves management goals without being unnecessarily expensive or inhumane) requires a better understanding of the conservation outcomes of different pest control regimes (Warburton \& Norton 2009).

Understanding the relative benefits of managing the impacts of forest loss versus the impacts of invasive mammals is also complicated by the fact that these threats may interact. For example, impacts of forest loss may weaken following pest control if forest loss affects native species by driving changes in the abundance of invasive mammals (Chalfoun et al. 2002; Ruffell et al. 2014). Alternatively, benefits of pest control may be greater in low- rather than high-cover landscapes, if decreased connectivity in low-cover landscapes reduces rates of reinvasion by pests from surrounding uncontrolled forests. The potential for such interactions has only recently been recognised, but they are potentially a critical aspect of effectively managing ecological systems that are impacted by multiple threats (Laurance \& Cochrane 2001; Didham et al. 2007).

In this study, we used bird count data from a regional biodiversity monitoring programme, supplemented by our own field surveys, to measure the richness and abundance of native forest birds within lowland forest sites (median elevation: 82 $\mathrm{m}$ above sea level) across mainland northern New Zealand. These sites varied widely in terms of the amount of native forest cover in the surrounding landscape $(<1-100 \%)$ and the category of pest control in place (ranging in intensity from no control to complete eradication). Sites also covered wide gradients of native forest cover within each category of pest control, allowing us to test for interaction effects. Our aim was to improve understanding of how to conserve native forest birds in lowland landscapes, by measuring the extent to which bird communities change in response to: (1) changing levels of forest cover, (2) the presence and category of pest control, and (3) the interacting effects of forest cover and pest control.

\section{Methods \\ Location of bird sampling sites}

The majority of sampling sites were selected and surveyed by Auckland Council ecologists as part of the council's Terrestrial Biodiversity Monitoring Programme(TBMP), which measures biodiversity values by systematically sampling plant, bird, and pest mammal communities in native forest throughout the region. As part of this programme, sampling sites were placed at grid-intersection points on a $4 \mathrm{~km}$ grid overlaid across the entire region (Figure 1). Where grid intersections did not fall on native forest habitat, a sampling location was randomly selected within the nearest forest patch, provided that this patch was within $2 \mathrm{~km}$ of the grid intersection. In addition, areas of special conservation interest (e.g. areas under intensive pest management) were surveyed at higher spatial resolution by

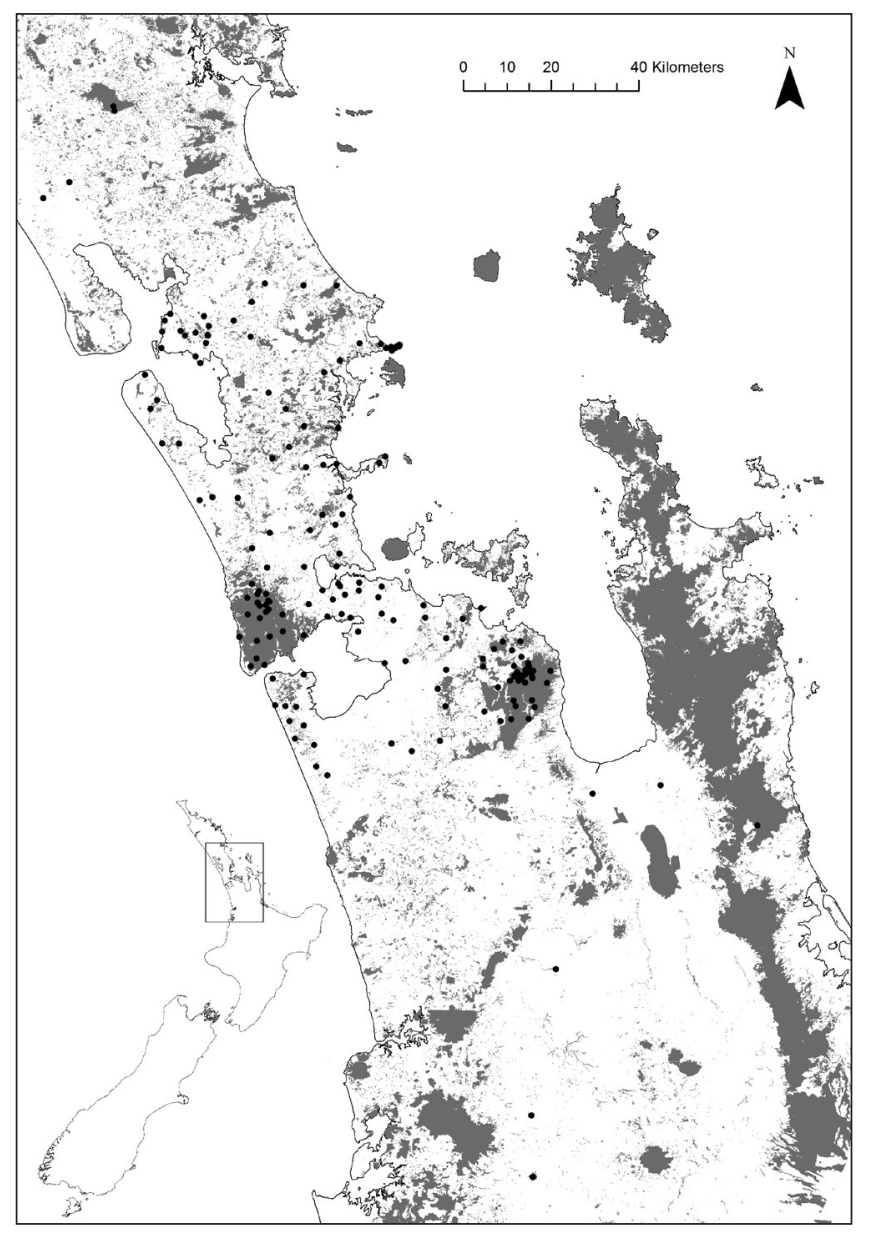

Figure 1. Locations of bird sampling sites. Shading shows the distribution of native forest, derived from the 'mānuka and/or kānuka', 'broadleaf indigenous hardwoods', and 'indigenous forest' layers of the New Zealand land cover database version 2. 
placing additional sampling sites at the intersections of either $2 \mathrm{~km}, 1 \mathrm{~km}$, or $500 \mathrm{~m}$ grids nested within the $4 \mathrm{~km}$ grid.

We used data from the 2009-2014 sampling period of the TBMP; however, not all sampling sites selected for the programme were included in our analysis. First, some private land owners did not give permission to survey on their land. Second, the program included sites on several of the Hauraki Gulf islands, which we excluded because the effects of pest control were likely to differ compared with mainland sites due to reduced recolonisation by pests and reduced dispersal by birds.

Preliminary analysis of the distribution of the TBMP sampling sites suggested that some of our pest control and forest cover predictor variables were either confounded or were not measured across their full range. Specifically, sampling sites with no pest control only occurred in landscapes with relatively low levels of forest cover, and there were only a handful of sampling sites in landscapes with very low levels of forest cover. Moreover, sampling sites under high-intensity pest control appeared to occur predominantly in a small number of (often very large) forest patches. To redress these limitations of the TBMP program, we conducted a targeted search for additional sampling locations elsewhere in the Auckland region, and in the adjacent Northland and Waikato regions (see Appendix S1 in Supplementary Material). This resulted in an additional ten sites across Northland and Waikato that we (JR) surveyed in 2012 using identical methods to those used in the TBMP programme: six sites with very low levels of forest cover $(<3 \%)$, three sites in large forest patches that were located in landscapes with very high forest cover but no pest control, and one site in an additional forest patch under high-intensity rat and possum control (Figure 1). Combined with the TBMP programme, our study included a total of 195 sampling sites.

\section{Sampling birds}

Birds were surveyed with five-minute bird counts, the standard method for quantifying the relative abundance of terrestrial birds in New Zealand (Hartley 2012), between November and December (i.e. early summer) each year. Each sampling site was surveyed three times over the course of a single day, beginning at least 2 hours after sunrise and ending before 1 PM, and with an interval of at least 1 hour between counts. All birds were included in counts regardless of their distance from the observer. For each sampling site, we measured the relative abundance of each species that occurred (i.e. the total number of individuals recorded across all three counts; hereafter 'abundance'), as well as species richness (i.e. the number of native forest species recorded; hereafter 'richness') and total relative abundance (i.e. the total number of individuals recorded from all native forest species; hereafter 'total abundance'). We note that these community-level indicators may be influenced by the composition of the bird community at each sampling site, in addition to its richness and abundance per se, since conspicuous species may contribute disproportionately to estimated values. Nonetheless, we believe that they still provide useful information on the health of the native bird communities sampled. We defined 'native forest' species based on the habitat descriptions of Heather and Robertson (2005) and the digital encyclopaedia of New Zealand birds (www. nzbirdsonline.org.nz, accessed March 2014) (see Table S1 in Supplementary Material).

\section{Measuring forest cover}

We quantified levels of forest cover in the landscape surrounding each sampling site with ArcGIS version 10.0, using land cover data from the New Zealand land cover database version 2 ('LCDB'; MfE 2004). We measured percent forest cover within a $1 \mathrm{~km}$ radius of each sampling site, after a preliminary analysis found that this radius typically predicted native bird abundance and richness as well as or better than other radii considered (see Table S2 in Supplementary Material). We defined 'forest' as the 'indigenous forest', 'broadleaf indigenous hardwoods', and 'mānuka and kānuka' categories of the LCDB2, based on a previous analysis which found that the distribution of native forest birds was best described by this combination of LCDB2 categories (JR, unpubl. data).

\section{Categorising pest control}

We categorised the type of pest control in the landscape surrounding each sampling site (i.e. within a $1 \mathrm{~km}$ radius) using the GIS maps produced by Ruffell et al. (2015). In that study, we mapped all major pest control operations in our study region based on information from all organisations involved in largescale mammalian-pest control in the Northland, Auckland, and Waikato regions (the Department of Conservation (DOC), TBfree New Zealand, Royal Forest and Bird Protection Society, regional and local councils, and local community groups). We note that this approach was unlikely to capture very small pest control operations, such as individual landowners controlling pests on their own property, or possum control by commercial fur trappers. However, fur trappers typically move on before possum densities are reduced to the levels required to benefit native biodiversity (Brockie 1982; Jones et al. 2012). The operations that we identified fell into the following five broad categories (reproduced from Ruffell et al. 2015).

(1) Eradication ('E'), which were areas enclosed by predatorproof fences where all rats, possums, mustelids, and cats had been eradicated.

(2) High-intensity rat and possum control ('HRP'), which was defined as ongoing control of rats and possums at a level at least as intensive as that done in DOC's 'mainland island' programme. This programme aims to restore the ecosystems of six forest sites through intensive control of multiple pest species (Saunders \& Norton 2001). Following descriptions of the pest control operations carried out at these mainland islands (Gillies 2002; Gillies etal.2003), and from discussions with mainland island management staff, pest control operations were classified as 'high-intensity' if all of the following conditions were met: (a) poison bait stations, targeting rats and possums, were placed at an average density of $>1$ per $1.5 \mathrm{ha}$; (b) bait stations were active at least over spring and summer; and (c) bait was replaced at least every 12 weeks during this active period. High-intensity rat and possum control operations have been shown to reduce indices of rat and possum abundance to low levels in our study region (Ruffell et al. 2015). These operations typically also undertook intensive mustelid control.

(3) Low-intensity rat and possum control ('LRP'), where control was targeted at both rats and possums, but not at a 'mainland island' level of intensity.

(4) Periodic possum control ('PP'), where target areas were periodically controlled for possums with a return time of 1-7 years. We note that the large variability in return time 
among these operations meant that some PP operations may have been considerably better at suppressing possum populations than others. However, we did not separate PP operations further, because (1) some operators could not give precise estimates of return times, and (2) individual operations sometimes had variable return times (Ruffell et al. 2015). Periodic possum control operations did not actively target other pest species, although there may have been by-kill, especially of ship rats.

(5) No pest control ('NC').

We note that all poisoning operations in our study area used ground-based application of baits, whereas throughout much of New Zealand baits are applied aerially (Wright 2011). After mapping pest control operations in each of our study landscapes, we found that the category of pest control at the sampling site closely reflected the dominant type of pest control in the wider landscape (see Appendix S2 in Supplementary Material). Therefore, we used the category of pest control at each sampling site as the metric of pest control in our statistical models, noting that this represented both site- and landscapelevel pest control. Pest control categories were sampled with reasonable intensity ( $\mathrm{n} \geq 27$ sampling sites) across the full range of values of native forest cover $(\sim 1-100 \%)$. An exception was the eradication category, which was sampled with 12 sampling sites across forest cover values ranging from $12-36 \%$.

We included all pest control operations in our main analysis, regardless of how recently they began. However, there may have been a time lag between the initiation of pest control and the realisation of benefits to bird communities. Therefore we conducted a sensitivity analysis in which we re-modelled our data after excluding recent operations (those that began $<5$ years before the date of survey), to examine whether our results were sensitive to potential time lags between the initiation of pest control and changes in the bird community.

\section{Measuring potentially confounding variables}

There were a number of other variables in our study region that could plausibly influence our measurements of bird richness and abundance. If correlated with native forest cover or pest control category, these variables could cause us to infer spurious relationships between native forest cover, pest control, and bird richness or abundance. We identified local vegetation characteristics, latitude, characteristics of the surrounding landscape (level of urbanisation and cover of pine plantations), climatic/topographical variables (mean and minimum temperature, slope, and altitude), and survey conditions during bird counts as potentially confounding variables. We measured the levels of these variables at each of our bird sampling sites, and examined whether they were correlated with native forest cover or pest control category (see Appendix S3 in Supplementary Material). This exercise revealed five variables that were significantly related to either pest control category or native forest cover: four 'survey conditions' variables (survey date, noise level, rain level, and minutes since dawn), and urbanisation category (Appendix S3). We included these variables in our statistical models to account for their effects while estimating relationships between native forest cover, pest control category, and native forest birds, after using variance inflation factors to confirm that the inclusion of these variables did not cause unacceptable multicollinearity in our models (Appendix S3). Two more variables, 'vegetation class' and 'climate PCA' (a principal components axis that represented all climatic and topographical variables; Appendix S3) were also significantly related to native forest cover, but preliminary modelling suggested that they had high variance inflation factors and so were likely to affect our ability to accurately estimate model parameters (Zuur et al. 2010). Therefore, we did not include vegetation class or climate PCA in our statistical models. However, we did conduct a sensitivity analysis in which we re-modelled our data while including these variables, to check whether their exclusion from our main analysis influenced our results.

\section{Statistical analyses}

Six of the 13 native forest species that we recorded were sufficiently common (detected at $>25 \%$ of sampling sites) for us to model the effects of forest cover and pest control category on their relative abundances: kererū, tūī, fantail, grey warbler, silvereye, and tomtit (see Table S1 for a list of all species recorded, together with Latin names). In addition, we modelled the effects of forest cover and pest control category on total abundance and species richness.

We used generalised linear mixed models (GLMMs) to estimate how these response variables changed with changing levels of native forest cover and pest control category. We modelled each response variable as a function of native forest cover, pest control category, and our five confounding variables. Each model also contained forest patch identity and observer identity as random factors to account for non-independence of sampling sites within areas of contiguous forest and bird counts by the same observer, respectively. We ran two models for each response variable, a 'main effects' model (which specified only main effects of pest control category and forest cover) and an 'interaction effects model' (which also specified an interaction between these variables).

We initially ran these models as Poisson GLMMs in R v 3.1.3 (R Core Team 2015). However, validation checks revealed that Poisson GLMMs were not valid for any response variable. While there was no evidence of spatial autocorrelation in our data, we found significant overdispersion and unacceptable patterning in plots of model residuals. Therefore, we updated each model, replacing the Poisson distribution with (1) the overdispersed Poisson (by adding an observation-level random effect to the model), (2) the negative binomial, (3) the zero-inflated Poisson, (4) the zero-inflated overdispersed Poisson, and (5) the zero-inflated negative binomial. We ran these models using the R packages ' $1 \mathrm{me} 4$ ', for the Poisson and negative binomial distributions, and 'glmmADMB', for the zero-inflated distributions (Bates et al. 2011; Bolker et al. 2012). For each model we selected the distribution that best met model assumptions, as judged by plots of model residuals (Table 1). In all cases the selected distribution produced residual plots that had no obvious patterning (beyond that expected for models of count data), and produced autocorrelation plots that showed no evidence of spatial autocorrelation. An exception was the response variable 'tomtit abundance', for which none of our distributions produced valid models. We ultimately had to use alternative methods to model tomtit abundance (see Appendix S4 in Supplementary Material).

Once we had identified a valid distribution for each response variable, we used AIC to examine whether there was evidence that forest cover and pest control category interacted in their effects. We compared the AIC of the 'main effects' and 'interaction effects' models for each response variable, selecting the single-best model for subsequent inference if there was good evidence that it was the better model (i.e. a 
Table 1. Models used to assess the effects of pest control and forest cover on native forest birds. For each response variable, AIC was used to measure support for two candidate models: a 'main effects only' model (PC + FC) and a 'main effects plus interaction' ( $\mathrm{PC} * \mathrm{FC})$ model. Statistical inference was based solely on the AIC-best model when it was the clear 'winner' (i.e. the alternative model had $\triangle \mathrm{AIC}>4$ ), but was based on model-averaged parameters otherwise. Models used for inference are shown in bold. All models also included five additional fixed effects to control for confounding, as well as two random effects.

\begin{tabular}{lccc}
\hline & & \multicolumn{2}{c}{$\Delta$ AIC of Model } \\
\cline { 3 - 4 } Response variable & Distribution & PC + FC & PC * FC \\
\hline Kererū abundance & Zero-inflated overdispersed Poisson & $\mathbf{0 . 0 0}$ & $\mathbf{0 . 7 2}$ \\
Tūī abundance & Zero-inflated negative binomial & $\mathbf{0 . 0 0}$ & 6.76 \\
Grey warbler abundance & Zero-inflated Poisson & $\mathbf{0 . 0 0}$ & 5.68 \\
Fantail abundance & Zero-inflated negative binomial & $\mathbf{0 . 0 0}$ & $\mathbf{0 . 1 7}$ \\
Silvereye abundance & Zero-inflated negative binomial & $\mathbf{0 . 0 0}$ & $\mathbf{1 . 4 4}$ \\
Tomtit abundance & Zero-inflated negative binomial & $\mathbf{0 . 0 0}$ & $\mathrm{n} / \mathrm{a}^{\mathrm{a}}$ \\
Total abundance & Overdispersed Poisson & $\mathbf{0 . 0 0}$ & 6.62 \\
Species richness & Overdispersed Poisson & $\mathbf{0 . 0 0}$ & 4.25 \\
\hline
\end{tabular}

${ }^{\mathrm{a}}$ Interaction model would not converge for tomtit.

$\Delta \mathrm{AIC}>4$ ) or averaging parameter estimates and confidence intervals across both models when evidence was weak $(\triangle \mathrm{AIC}$ $\leq 4)$. We used the 'model.avg' function of the 'MuMIn' package for model averaging (Barton 2013).

We initially log-transformed forest cover prior to statistical modelling, under the expectation that the relationship between forest cover and each of our response variables would approximate a standard 'species-area curve': a straight-line relationship between the log of forest cover and the log of the response, resulting in a linear or curvilinear relationship when these variables are back-transformed (Rosenzweig 1995). Each of our models used a log-link function (i.e. the logarithm of the response was modelled as a linear function of the predictors), so log-transforming forest cover forced these models to fit a species-area curve to the data. Comparison of our models containing log-transformed forest cover with their untransformed counterparts revealed that the former provided a better fit to the data, or at least an equivalent fit $(\triangle \mathrm{AIC}<1)$, for all response variables except for silvereye abundance (for which models with log-transformed forest cover would not converge) and fantail abundance (for which models with log-transformed forest cover provided a worse fit, with $\triangle \mathrm{AIC}$ $>4$ ). Therefore, we ran all models with log-transformed forest cover, except for our silvereye and fantail models, which used untransformed forest cover.

\section{Results}

For every response variable, the model that contained only the main effects of pest control category and forest cover was better than the model that also included an interaction term, as judged by AIC (Table 1). However, this evidence was relatively weak $(\triangle \mathrm{AIC}<2)$ for fantail, kererū, and silvereye abundance, so we averaged parameters across both the main effects and interaction effects models for these species (Table 1). Even so, model-averaged interaction terms were not significant for the fantail, kererū, or silvereye models (Figure 2).

Forest cover had a significant positive effect on grey warbler abundance, tūi abundance, and total abundance, as well as a marginally non-significant effect $(p=0.07)$ on species richness (Figure 2). Predicted values for these response variables followed the 'decelerating curve' relationship that is typical of species-area curves, being relatively insensitive to changing forest cover in heavily forested landscapes, but declining rapidly below c. 5-10\% forest cover (Figure 2 ). This sensitivity to low levels of forest cover was even more marked for tomtits, with an apparent threshold relationship between tomtit abundance and forest cover: tomtits were relatively common above c. $25 \%$ forest cover, but absent below $25 \%$ cover regardless of pest control category (Figure 2, Appendix S4). We were unable to model this threshold relationship despite attempting a wide range of modelling procedures, and we ultimately resorted to modelling tomtit abundance after excluding sites with $<25 \%$ forest cover (Appendix S4). Therefore, we could not test the statistical significance of the forest cover effect on tom tits across the full range of forest cover values, but graphing the data showed a strong relationship that seemed extremely unlikely to have occurred by chance alone (Figure 2). Forest cover also had a marginally non-significant negative effect on fantail abundance. Silvereye and kererū were the only species for which there was no evidence of a forest cover effect (Figure 2).

Pest control appeared to benefit surprisingly few species. Most species either were not significantly more abundant at pest controlled sites, regardless of the pest control category (fantail, silvereye, and tomtit), or were significantly less abundant (grey warbler; Figure 2). By contrast, kererū and tūī did appear to benefit from pest control, and this effect was consistent across most (kererū) or all (tūī) pest control categories. The size of this effect also corresponded to the intensity of pest control. Model-predicted values suggested that sites under eradication control had far higher abundance of kererū and tūī than sites under all other pest control categories, and that sites under HRP control had higher abundance than sites under LRP and PP control (Figure 2).

Species richness and total abundance showed the same responses to pest control as kererū and tūi abundance. Values were highest at sites under eradication and HRP control and lowest at sites under no control, although for species richness only the effect of eradication was significant (Figure 2). These effects appeared to be driven largely by the responses of kererū and tūi to pest control, since, with the exception of the effect of eradication on total abundance, they became non-significant 

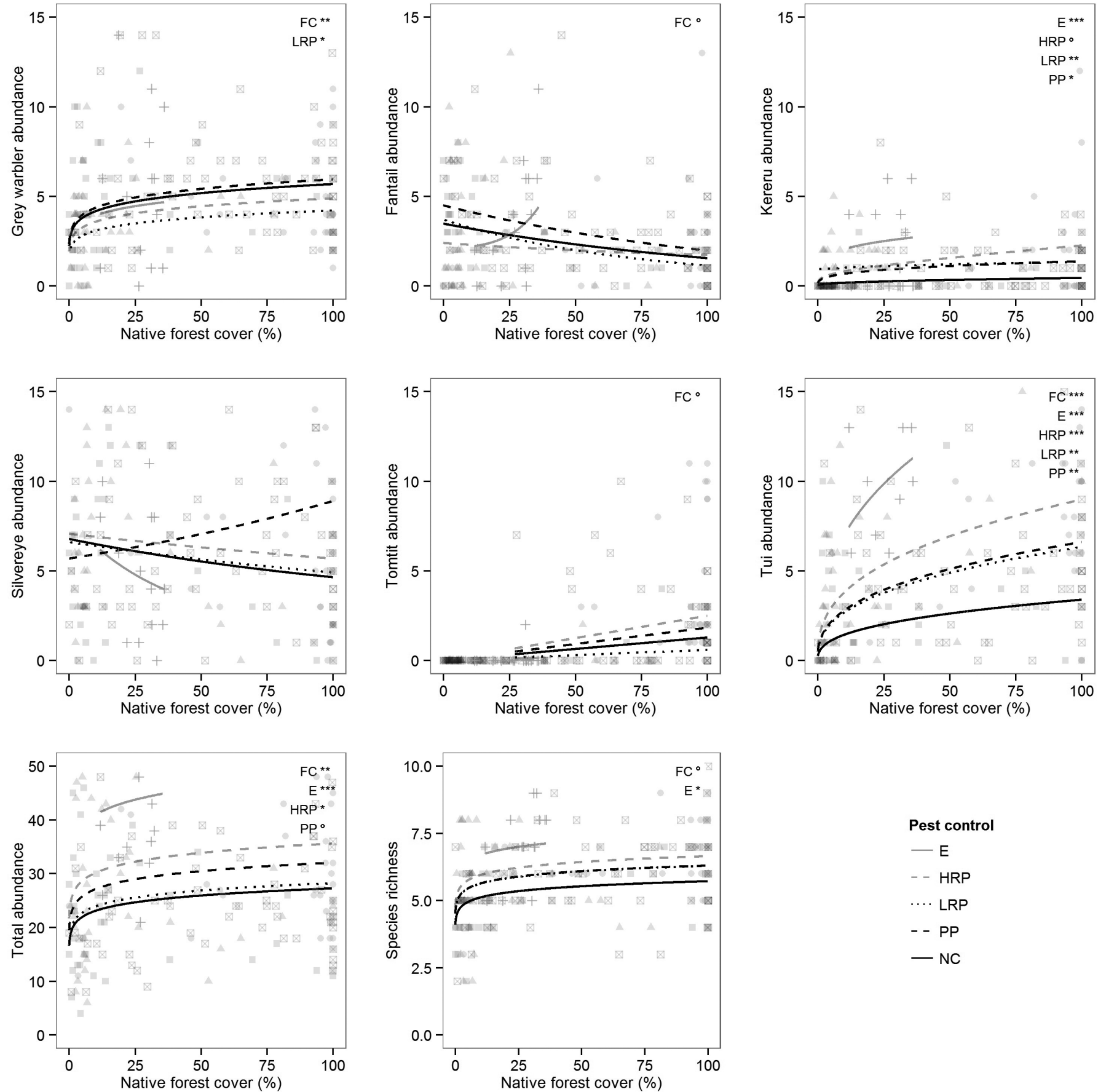

Figure 2. Model-predicted values for the effects of native forest cover and pest control category on native forest birds. Pest control categories are: $\mathrm{E}=$ eradication; HRP = high-intensity rat and possum control; LRP = low-intensity rat and possum control; $\mathrm{PP}=$ periodic possum control; $\mathrm{NC}=$ no control. Truncated values for eradication predictions reflect the reduced range over which forest cover was measured for this pest control category, while truncated values for the 'tomtit abundance' plot reflect the fact that we could not model data for sites with $<25 \%$ forest cover. Raw data are also shown on the plots: crosses, circles, triangles, crossed squares, and squares represent E, HRP, LRP, PP, and NC control, respectively. Note that model-predicted values account for effects of confounding variables, whereas raw data do not. Lettering and asterisks at the top-right of each panel denote significant effects of forest cover (FC), pest control (E; HRP; LRP; and PP), and their interaction: $* \mathrm{p}<0.05 ; * * \mathrm{p}<0.01 ; * * * \mathrm{p}<0.001 ;{ }^{\circ} 0.05<\mathrm{p}<0.10$. A full list of parameter estimates, standard errors, and $p$-values for the effects of forest cover, pest control, and confounding variables is provided in Table S3 (see Supplementary Material). 
when the data were re-modelled after excluding tūī and kererū observations (JR, unpubl. data).

When we repeated our analysis after excluding pest control operations that began $<5$ years before the date of survey (to examine whether time lags between the initiation of pest control and changes in bird richness and abundance may have influenced our results), we found the results were generally the same as in our main analysis (see Figure S1 in Supplementary Material). However, this analysis did raise doubts about whether PP and LRP control provided any benefits to bird communities. Although our main analysis suggested that both PP and LRP control significantly increased kererū and tūī abundance, our sensitivity analysis suggested that their only effect was an increase in tūi abundance at sites under LRP control (Figure S1). The effects of forest cover were also slightly stronger in this reanalysis, with the near-significant effects on fantail, tomtit, and species richness becoming significant.

Our sensitivity analysis that re-modelled the data while controlling for the effects of our 'vegetation class' and 'climate PCA' variables (excluded from our main analysis because of their high variance inflation factors) indicated that they did not strongly influence results (see Figure S2 in Supplementary Material).

\section{Discussion}

Conservation managers throughout the world face the challenge of allocating scarce conservation resources to the management of multiple co-occurring threats. In New Zealand's lowland environments, effective conservation decision-making requires an understanding of the relative benefits of managing the impacts of invasive mammals versus managing the impacts of native forest loss. Our results suggest that changing levels of forest cover and invasive-mammal control can affect the abundance and richness of native forest birds, but that the occurrence and magnitude of these effects are context-dependent. The marginal effect of varying forest cover depended strongly on how much forest was already in the landscape, while the effects of pest control were limited to a small subset of species and varied widely depending on the category of pest control in place. These results provide important insights into the benefits of different management strategies that aim to conserve native forest bird communities in landscapes impacted by forest clearance and invasive mammals.

\section{Effects of forest cover on native forest birds}

Most of our response variables were affected by forest cover, and model-predicted values suggested that these effects were strongly non-linear. Response variables were typically relatively invariant to changing levels of forest cover in heavily-forested landscapes, but declined rapidly once cover dropped below c. 5-10\%. This suggests that managing levels of forest cover may be relatively unimportant for conserving native forest bird communities in landscapes with high forest cover, but should be a priority in landscapes where cover is near or below $5-10 \%$. Further forest clearance in these lowcover landscapes is likely to have large impacts on native bird communities, while even small increases in forest cover may produce large benefits. Other management actions that aim to mitigate the impacts of native forest loss, such as using pine plantations to connect isolated remnants of native forest (Norton \& Miller 2000; Ruffell et al. 2016), may also provide much greater benefits in low-cover than high-cover landscapes.
While most response variables that were affected by forest cover declined rapidly when cover dropped below c. 5-10\%, tomtit abundance showed a different response. Tomtits were absent from landscapes with $<25 \%$ forest cover but relatively common at higher levels of forest cover, regardless of the type of pest control in place. Consequently, while it appears that maintaining forest cover above $5-10 \%$ would avoid many of the impacts of forest loss on native forest bird communities in our study system, it is unlikely that this approach would be sufficient to maintain tomtits in the landscape. The mechanism underpinning the effect of forest cover on tomtits is not clear, although we note that habitat fragmentation (declining patch size, increasing patch isolation, and increasing exposure to habitat edges) tends to increase rapidly once forest cover drops below c. 10-30\% (Andrén 1994; Swift \& Hannon 2010). Tomtits may be more sensitive to these fragmentation effects than other species. However, we were unable to model the relationship between tomtit abundance and forest cover at sites with $<25 \%$ cover, and so could not measure forest cover effects while controlling for potentially confounding factors such as elevation or climatic variables. It may be that these variables, rather than forest cover or fragmentation effects per se, drove the threshold effect that we observed.

\section{Effects of pest control on native forest birds}

Invasive mammals are widely believed to be the primary threat to native forest birds in New Zealand, but four of the six species that we modelled (grey warbler, fantail, silvereye, and tomtit) were no more abundant in pest controlled landscapes than in landscapes without pest control. There are several potential explanations for this finding. First, the pest control operations in our study system may have been unsuccessful at reducing pest abundance. This is possible for LRP and PP control, since we previously found that these pest control categories did not measurably reduce indices of rat and possum abundance in a 'snapshot survey' across the same sampling locations (Ruffell et al. 2015). Second, we may have been unable to detect real effects of pest control because of insufficient statistical power. We sampled birds across pre-existing gradients of forest cover and pest control intensity, which meant that preexisting differences among sites increased variability in the data and made trends more difficult to detect. Nonetheless, we had sufficient statistical power to detect forest cover effects on these species, and pest control effects on tūî and kererū, suggesting that any effects of pest control were relatively weak. Finally, invasive mammals may have had negligible impacts on grey warbler, fantail, silvereye, and/or tomtit abundance. Although rats and possums are known to eat the eggs, nestlings, and adults of these species, there is little evidence that this individual-level predation translates into population-level impacts (i.e. reduced abundance or viability) (see Table 4 of Innes et al. 2010). Indeed, Innes et al. (2004) found that the relative abundance of grey warbler, fantail, silvereye, and tomtit did not measurably increase following pest control, while O'Donnell and Hoare (2012) found the same for silvereye and tomtit. It seems likely that predation on some or all of these species is often compensatory, killing individuals but having limited impacts on populations (Newton 1998; Evans 2004).

In contrast to the other species studied, kererū and tū $\overline{1}$ were significantly more abundant in pest-controlled landscapes than in landscapes without any control. These responses are unsurprising, given that the relative abundance of both species has increased in response to pest control elsewhere (Innes et al. 2004). Pest control appears to be an important 
tool for increasing the abundance of these species, at least for eradication and HRP regimes. Nonetheless, model-predicted values suggested that tūī would still be reasonably common at sites without pest control, provided that forest cover was sufficiently high, but that their relative abundance would decline towards zero at pest controlled sites as forest cover approached $0 \%$. This suggests that maintaining or increasing forest cover may be more important than pest control for maximising tūi abundance in landscapes with very low levels of forest cover.

Although our main analysis suggested that both LRP and PP control increased kererū and tūi abundance, our sensitivity analysis suggested that PP did not benefit either species, and that LRP only increased tūi abundance. The reason for these differences between our main and sensitivity analyses is that pest control and forest cover were correlated, with pest control typically occurring in more forested landscapes. Our multiple regression models allowed us to estimate the effects of pest control after controlling for the effects of forest cover, and vice versa, but doing so accurately required that pest control was correctly defined. In other words, excluding pest control operations that were $<5$ years old may have resulted in real pest control effects being falsely attributed to forest cover effects, while including all pest control operations may have resulted in real forest cover effects being falsely attributed to pest control effects. Unfortunately, we cannot determine which of these scenarios is correct, although we note that the results from our sensitivity analysis are consistent with our previous work, which showed that PP and LRP control did not measurably reduce indices of rat and possum abundance in a 'snapshot survey' across the same set of study sites (Ruffell et al. 2015). Determining the extent to which PP and LRP control benefit native bird communities should be a priority for future research. These types of operation dominate pest control in New Zealand, costing millions of dollars and killing large numbers of sentient animals each year (Warburton \& Norton 2009; Warburton et al. 2009; Wright 2011). However, with the exception of the effect of LRP on tūī, we are uncertain whether they benefited a single response variable in our study system.

The species for which we modelled the effects of forest cover and pest control were only those that were most common across our study region, occurring at $>25 \%$ of sites (although species richness and total abundance included all species recorded). It is likely that less common species, whose abundance we did not specifically model, were more strongly influenced by pest control. We occasionally recorded six additional native forest species: morepork, hihi, North Island robin, North Island kokako, kaka, and whitehead (Table S1). With the exception of morepork, these species are known to be strongly impacted by predation from invasive mammals (Innes et al. 1999; Moorhouse et al. 2003; Armstrong et al. 2006; Leuschner 2013). However, in our study system, hihi, robin, and whitehead only occur where they have been reintroduced to intensively pest-managed sites. Kokako only occur where they have been reintroduced and at a single remnant population, and kaka may only occur when they range away from breeding sites on predator-free islands. Since these species have already become locally extinct in most lowland landscapes, pest control typically will not benefit them unless it is combined with reintroduction. A possible exception is kaka, which ranges widely away from breeding sites (Moorhouse 2013) and so may be able to recolonise pest-controlled sites naturally.

Our study examined the effects of forest loss and pest control on native bird communities in lowland podocarpbroadleaf forest, but we note that New Zealand forests are often dominated by beech (Fuscaspora spp. and Lophozonia menziesii), rather than podocarp-broadleaf species (Wardle 1984). While beech and podocarp-broadleaf forests share many of the same bird species (O'Donnell \& Hoare 2012; this study), there are at least two important differences that may influence the applicability of our results to beech forest systems. First, beech forests may be less productive than podocarp-broadleaf forests (Choquenot \& Ruscoe 2000), potentially influencing (1) rates of nest predation, because adult birds may spend more time foraging and less time defending nests (Zanette et al. 2000); and (2) the amount of forest required to support viable bird populations, because the density of birds may be lower. Second, beech forests experience periodic irruptions of mice, rats, and stoats as a result of mast seeding, which may cause rates of predation on native birds to vary dramatically across years (O'Donnell 1996). The relative benefits of managing invasive mammals versus managing forest loss may differ between beech and podocarp-broadleaf forests, and we suggest that conservation managers should exercise caution when applying our findings to beech forest systems.

\section{Costs of managing forest cover and invasive mammals}

Our analysis suggests that both managing levels of forest cover and controlling invasive mammals can play an important role in increasing the abundance and richness of native forest bird communities in lowland New Zealand. However, real-world management decisions will depend on the costs of particular management strategies in addition to their effectiveness, and this is something that we did not account for in our study. For example, eradication appeared to produce much larger increases in bird abundance than other types of pest control, but may be prohibitively expensive at most mainland sites (Scofield et al. 2011). Similarly, managers wishing to reverse the effects of historic forest loss may not have the resources to conduct large-scale reforestation, although we suggest that there may also be alternative, less resource-intensive options. For example, it may be possible to undertake 'passive reforestation' by protecting scrub vegetation that is a pre-cursor to mature native forest (Ewers et al. 2006), to use exotic plantations to provide substitute habitat(Norton \& Miller 2000; Ruffell 2015), or to configure plantings so that they address the mechanisms underlying impacts of forest loss while minimising the amount of reforestation required (for example, creating corridors among isolated forest remnants or buffering edge effects; Didham et al. 2012).

Social and ethical 'costs' may also influence the feasibility of different management strategies. For example, some pest control regimes may not be tenable because of ethical or social issues such as the use of inhumane anticoagulant poisons or the application of toxins onto public land (Maguire 2004; Warburton \& Norton 2009; Beausoleil et al. 2010; Russell 2014). Similarly, there may be pressure to maintain or increase levels of native forest cover in a landscape because of the cultural or recreational values that native forests provide, even if pest control would have provided greater benefits to biodiversity (Jamieson 2008). Real-world decisions about whether to manage impacts of forest loss or impacts of invasive mammals should account for these constraints, in addition to the effectiveness of different management strategies per se (Tulloch et al. 2015). 


\section{Conclusion}

Our study provides a useful first step in understanding how best to conserve native forest bird communities in New Zealand's lowland environments. We found that the benefits of managing levels of forest cover and conducting pest control are likely to be strongly context-dependent, varying with the amount of forest cover in the landscape and the intensity of pest control. We also found that pest control may benefit relatively few species, unless it is coupled with the reintroduction of pestsensitive species that have already become locally extinct in most lowland landscapes. Our results will allow managers to predict the response of the bird community to different management scenarios (increasing or decreasing levels of forest cover, and/or changing the intensity of pest control) while accounting for this context dependence, at least in our northern New Zealand study system. Combining these predictions with knowledge of the financial, ethical, and social constraints of different management options should provide a solid foundation for making effective decisions about how to conserve forest bird communities in lowland environments.

\section{Acknowledgements}

We thank Craig Bishop, Todd Landers, and Jade Khin for providing access to the TBMP dataset, and we acknowledge the many Auckland Council field ecologists who completed the TBMP surveys. For our own surveys, we thank Ken Lendrum, Ean Ballentyne, Richard Riddell, Roger and Rachel Kidd, Peter and Tracy Mapson, Andrew Sinclair, Gerald Mannion, and David and Susan Dreadon for providing access to their forest remnants, and staff from the QE2 Trust for facilitating landowner contact. We are grateful also to the many pest control operators throughout Northland, Auckland, and Waikato who provided us with the information necessary to map pest control throughout our study area. JR was supported by a Hackett postgraduate scholarship at the University of Western Australia during the preparation of the manuscript.

\section{References}

Andrén H 1994. Effects of habitat fragmentation on birds and mammals in landscapes with different proportions of suitable habitat - a review. Oikos 71: 355-366.

Armstrong DP, Raeburn EH, Lewis RM, Ravine D 2006. Estimating the viability of a reintroduced New Zealand robin population as a function of predator control. Journal of Wildlife Management 70: 1020-1027.

Barnagaud J-Y, Barbaro L, Papaïx J, Deconchat M, Brockerhoff EG 2014. Habitat filtering by landscape and local forest composition in native and exotic New Zealand birds. Ecology 95: 78-87.

Barton K2013. MuMIn: multi-model inference. Version 1.9.13.

Bates D, Maechler M, Bolker B 2011. lme4: linear mixedeffects models using S4 classes. Version 0.999999-0.

Beausoleil N, Fisher P, Warburton B, Mellor D 2010. How humane are our pest control tools? Part 1. Vertebrate toxic agents and kill traps in mammal species. Christchurch, New Zealand, Ministry of Agriculture and Forestry. 148 p.

Bolker B, Skaug H, Magnusson A, Nielsen A 2012. glmmADMB: generalised linear mixed models using AD model builder. Version 0.8.1.
Brockie R 1982. Effect of commercial hunters on the numbers of possums, Trichosurus vulpecula, in Orongorongo Valley, Wellington. New Zealand Journal of Ecology 5: 21-28.

Chalfoun AD, Thompson FR, Ratnaswamy MJ 2002. Nest predators and fragmentation: a review and meta-analysis. Conservation Biology 16: 306-318.

Choquenot D, Ruscoe WA 2000. Mouse population eruptions in New Zealand forests: the role of population density and seedfall. Journal of Animal Ecology 69: 1058-1070.

Craig J, Anderson S, Clout M, Creese B, Mitchell N, Ogden J, Roberts M, Ussher G 2000. Conservation issues in New Zealand. Annual Review of Ecology and Systematics 31: 61-78.

Deconchat M, Brockerhoff EG, Barbaro L 2009. Effects of surrounding landscape composition on the conservation value of native and exotic habitats for native forest birds. Forest Ecology and Management 258: S196-S204.

Diamond JM 1984. Distributions of New Zealand birds on real and virtual islands. New Zealand Journal of Ecology 7: 37-55.

Didham RK, Tylianakis JM, Gemmell NJ, Rand TA, Ewers RM 2007. Interactive effects of habitat modification and species invasion on native species decline. Trends in Ecology \& Evolution 22: 489-496.

Didham RK, Kapos V, Ewers RM 2012. Rethinking the conceptual foundations of habitat fragmentation research. Oikos 121: 161-170.

DOC, MfE 2000. New Zealand Biodiversity Strategy. Wellington, New Zealand Department of Conservation and New Zealand Ministry for the Environment. $144 \mathrm{p}$.

Evans KL 2004. The potential for interactions between predation and habitat change to cause population declines of farmland birds. Ibis 146: 1-13.

Ewers RM, Kliskey AD, Walker S, Rutledge D, Harding JS, Didham RK 2006. Past and future trajectories of forest loss in New Zealand. Biological Conservation 133: 312-325.

Foley JA, Ramankutty N, Brauman KA, Cassidy ES, Gerber JS, Johnston M, Mueller ND, O'Connell C, Ray DK, West PC 2011. Solutions for a cultivated planet. Nature 478: 337-342.

Gillies C 2002. Managing rodents on the New Zealand mainland-what options are currently available? Summary of a workshop session at the Department of Conservation 'mainland island' hui, Omapere, 20-23 August 2001. Wellington, Department of Conservation. 20 p.

Gillies C, Leach M, Coad N, Theobald S, Campbell J, Herbert T, Graham P, Pierce R 2003. Six years of intensive pest mammal control at Trounson Kauri Park, a Department ofConservation "mainland island", June 1996-July 2002. New Zealand Journal of Zoology 30: 399-420.

Hartley LJ 2012. Five-minute bird counts in New Zealand. New Zealand Journal of Ecology 36: 268-278.

Heather BD, Robertson HA 2005. The field guide to the birds of New Zealand. Auckland, Penguin Books. 440 p.

Innes J, Hay R, Flux I, Bradfield P, Speed H, Jansen P 1999. Successful recovery of North Island kokako Callaeas cinerea wilsoni populations, by adaptive management. Biological Conservation 87: 201-214.

Innes J, Nugent G, Prime K, Spurr EB 2004. Responses of kukupa (Hemiphaga novaeseelandiae) and other birds to mammal pest control at Motatau, Northland. New Zealand Journal of Ecology 28: 73-81.

Innes J, Kelly D, Overton JM, Gillies C 2010. Predation and other factors currently limiting New Zealand forest birds. 
New Zealand Journal of Ecology 34: 86-114.

Jamieson D 2008. Ethics and the environment: an introduction. Cambridge, Cambridge University Press. 234 p.

Jones C, Barron M, Warburton B, Coleman M, Lyver POB, Nugent G 2012. Serving two masters: reconciling economic and biodiversity outcomes of brushtail possum(Trichosurus vulpecula) fur harvest in an indigenous New Zealand forest. Biological Conservation 153: 143-152.

Kelly D, Sullivan JJ 2010. Life histories, dispersal, invasions, and global change: progress and prospects in New Zealand ecology, 1989-2029. New Zealand Journal of Ecology 34: 207-217.

Laurance WF, Cochrane MA 2001. Synergistic effects in fragmented landscapes. Conservation Biology 15: 1488-1489.

Leuschner N2013. Whitehead. In: Miskelly C ed. New Zealand birds online. http://nzbirdsonline.org.nz (accessed 27 July 2015).

Maguire LA 2004. What can decision analysis do for invasive species management? Risk Analysis 24: 859-868.

MfE 2004. New Zealand land cover database 2 user guide. Wellington, New Zealand Ministry for the Environment.

Moorhouse R 2013. Kaka. In: Miskelly C ed. New Zealand birds online. http://nzbirdsonline.org.nz(accessed 27 July 2015).

Moorhouse R, Greene T, Dilks P, Powlesland R, Moran L, Taylor G, Jones A, Knegtmans J, Wills D, Pryde M 2003. Control of introduced mammalian predators improves kaka Nestor meridionalis breeding success: reversing the decline of a threatened New Zealand parrot. Biological Conservation 110: 33-44.

Munns WR Jr 2006. Assessing risks to wildlife populations from multiple stressors: overview of the problem and research needs. Ecology and Society 11: 23.

Newton I 1998. Population limitation in birds. London, Academic Press. 597 p.

Norton DA, Miller CJ 2000. Some issues and options for the conservation of native biodiversity in rural New Zealand. Ecological Management \& Restoration 1: 26-34.

Novacek MJ, Cleland EE 2001. The current biodiversity extinction event: scenarios for mitigation and recovery. Proceedings of the National Academy of Sciences 98: 5466-5470.

O’Donnell CFJ 1996. Monitoring mohua (yellowhead) populations in the South Island, New Zealand, 1983-93. New Zealand Journal of Ecology 23: 221-228.

O'Donnell CF, Hoare JM2012. Quantifying the benefits of longterm integrated pest control for forest bird populations in a New Zealand temperate rainforest. New Zealand Journal of Ecology 36: 131-140.

Parkes J, Murphy EC 2003. Management of introduced mammals in New Zealand. New Zealand Journal of Ecology 30: 335-359.

R Core Team 2015. R: a language and environment for statistical computing. Version 3.1.3. Vienna, R Foundation for Statistical Computing.

Riley J 2002. Mammals on the Sangihe and Talaud Islands, Indonesia, and the impact of hunting and habitat loss. Oryx 36: 288-296.

Rosenzweig ML 1995. Species diversity in space and time. Cambridge University Press. 460 p.

Ruffell J2015. Managing the impacts of habitat loss and invasive mammals on New Zealand forest birds. Unpublished PhD thesis, University of Western Australia. 245 p.

Ruffell J, Didham RK, Barrett P, Gorman N, Pike R,
Hickey-Elliott A, Sievwright KA, Armstrong DP 2014. Discriminating the drivers of edge effects on nest predation: forest edges reduce capture rates of ship rats (Rattus rattus), a globally invasive nest predator, by altering vegetation structure. PLoS ONE 9(11): e113098.

Ruffell J, Innes J, Bishop C, Landers T, Khin J, Didham RK 2015. Using pest monitoring data to inform the location and intensity of invasive-species control in New Zealand. Biological Conservation 191: 640-649.

Ruffell J, Clout MN, Didham RK 2016. The matrix matters, but how should we manage it? Estimating the amount of high-quality matrix required to maintain biodiversity in fragmented landscapes. Ecography. doi: 10.1111/ ecog.02097.

Russell JC 2014. A comparison of attitudes towards introduced wildlife in New Zealand in 1994 and 2012. Journal of the Royal Society of New Zealand 44: 136-151.

Sala OE, Chapin FS, Armesto JJ, Berlow E, Bloomfield J, Dirzo R, Huber-Sanwald E, Huenneke LF, Jackson RB, Kinzig A, Leemans R, Lodge DM, Mooney HA, Oesterheld M, PoffNL, Sykes MT, Walker BH, Walker M, Wall DH 2000. Global biodiversity scenarios for the year 2100. Science 287: $1770-1774$.

Saunders A, Norton DA 2001. Ecological restoration at mainland islands in New Zealand. Biological Conservation 99: 109-119.

Scofield R, Cullen R, Wang M 2011. Are predator-proof fences the answer to New Zealand's terrestrial faunal biodiversity crisis? New Zealand Journal of Ecology 35: 312-317.

Stevens H 2006. Native birds in forest remnants. Unpublished $\mathrm{PhD}$ thesis, University of Auckland. $200 \mathrm{p}$.

Swift TL, Hannon SJ 2010. Critical thresholds associated with habitat loss: a review of the concepts, evidence, and applications. Biological Reviews 85: 35-53.

Tulloch VJ, Tulloch AI, Visconti P, Halpern BS, Watson JE, Evans MC, Auerbach NA, Barnes M, Beger M, Chadès I 2015. Why do we map threats? Linking threat mapping with actions to make better conservation decisions. Frontiers in Ecology and the Environment 13: 91-99.

Warburton B, Norton BG 2009. Towards a knowledge-based ethic for lethal control of nuisance wildlife. The Journal of Wildlife Management 73: 158-164.

Warburton B, Cowan P, Shepherd J 2009. How many possums are now in New Zealand following control and how many would there be without it? Lincoln, Landcare Research New Zealand Ltd. 15 p.

Wardle J 1984. The New Zealand beeches: ecology, utilisation and management. New Zealand Forest Service. 447 p.

Wilson KA, Underwood EC, Morrison SA, Klausmeyer KR, Murdoch WW, Reyers B, Wardell-Johnson G, MarquetPA, Rundel PW, McBride MF, Pressey RL, Bode M, Hoekstra JM, Andelman S, Looker M, Rondinini C, Kareiva P, Shaw MR, Possingham HP 2007. Conserving biodiversity efficiently: what to do, where, and when. PLoS Biology 5(9): 1850-1861.

Wright J 2011. Evaluating the use of 1080: predators, poisons and silent forests. Wellington, New Zealand Parliamentary Commissioner for the Environment. 85 p.

Zanette L, Doyle P, Tremont SM 2000. Food shortage in small fragments: evidence from an area-sensitive passerine. Ecology 81: 1654-1666.

Zuur AF, Ieno EN, Elphick CS 2010. A protocol for data exploration to avoid common statistical problems. Methods in Ecology and Evolution 1: 3-14. 
Editorial board member: Dean Anderson

Received 29 December 2015; accepted 16 August 2016

\section{Supplementary Material}

Additional supporting information may be found in the online version of this article.

Appendix S1. Selecting additional sampling sites to supplement the Auckland Council monitoring program.

Appendix S2. Relationship between pest control at the sampling site and pest control in the wider landscape.

Appendix S3. Identifying and accounting for potentially confounding variables.

Appendix S4. Alternative statistical analyses for the tomtit data.

Figures S1. Model-predicted values for effects of native forest cover and pest control category on native forest birds, where pest control category was defined after excluding operations $<5$-yr old.

Figure S2. Model-predicted values for effects of native forest cover and pest control category on native forest birds, based on models that inclued vegetation class and climate variables to control potentially confounding effects.

Table S1. Native bird species recorded in our surveys, and whether we counted them as 'forest species' for our analysis.

Table S2. Levels of support for candidate models which examined the best landscape size for quantifying the effects of native forest cover on native forest bird communities across our sampling sites.

Table S3. Model coefficients for effects of forest cover, pest control, and potentially confounding variables on native forest birds.

The New Zealand Journal of Ecology provides online supporting information supplied by the authors where this may assist readers. Such materials are peer-reviewed and copy-edited but any issues relating to this information (other than missing files) should be addressed to the authors. 